\title{
Clinical Manifestation and Hematologic Interpretation of Pediatric Systematic Lupus Erythematosus at Initial Presentation: 2-Years Observation
}

\author{
Hasti Savira Yudiana, ${ }^{1}$ Reni Ghrahani, ${ }^{2}$ Adhi Kristianto Sugianli ${ }^{3}$ \\ ${ }^{1}$ Faculty of Medicine Universitas Padjadjaran, Indonesia, ${ }^{2}$ Department of Child Health Faculty \\ of Medicine Universitas Padjadjaran/Dr. Hasan Sadikin General Hospital, Bandung, Indonesia, \\ ${ }^{3}$ Department of Clinical Pathology Faculty of Medicine Universitas Padjadjaran/Dr. Hasan Sadikin \\ General Hospital, Bandung, Indonesiaa
}

\section{Abstract}

Background: Systemic Lupus Erythematosus (SLE) is an autoimmune disease characterized by a spectrum of clinical manifestations, immunological abnormalities, and varied laboratories results. In children, SLE manifestation is particularly more severe, involving more organs. Hematological manifestation has been known as the most common manifestation. The purpose of this study was to describe the clinical manifestations and hematologic interpretation of pediatric SLE at initial presentation.

Methods: This retrospective data collection study was conducted at the Department of Child Health Dr. Hasan Sadikin General Hospital Bandung on medical records from a two-year period of 20172018. The clinical manifestations were categorized into malar rash, discoid rash, photosensitivity, oral ulcers, arthritis, renal disorders, and neurological disorders. The hematologic interpretations were categorized into anemia, leukopenia, neutropenia, lymphopenia, and thrombocytopenia. Clinical manifestations and hematological interpretations were presented as occurrence percentages and stratified into three age-group of pre-pubertal, peri-pubertal, and post-pubertal.

Results: Among 79 pediatric SLE patients (median age 14 years old; IQR 11-16), female gender was predominant. Abnormalities hematologic interpretation occurs in more than half of the patients $(83.5 \%)$. Malar rash and anemia were the commonest findings among all age groups. Increased occurrence of neuropsychiatric and renal disorders were observed in all age-groups.

Conclusions: Malar rash and anemia are important findings among pediatric SLE patients. Furthermore, the occurrences of the neuropsychiatric and renal disorders are also important.

Keywords: Hematologic interpretation, neuropsychiatric, renal disorder, pediatric, systemic lupus erythematosus

\section{Introduction}

Systemic Lupus Erythematosus (SLE) is a complex multi-system autoimmune illness characterized by a broad spectrum of clinical manifestations, with immunological and laboratory abnormalities. It can affect all people of both genders and various races/ ethnicities, age groups, socioeconomic status, and others. The incidence of SLE in the world has reached $0.3-23.7$ per 100,000 population per year. ${ }^{1}$ The prevalence of SLE in the Asia
Pacific is $0.9-3.1$ per 100,000 populations per year. In addition, lupus is also considered an illness that has a fairly high mortality rate. In 2016, the Indonesian Ministry of Health reported a high mortality number of hospitalized lupus patients which was 550 out of 2,166 patients. $^{2}$

Pediatric SLE is defined as a systemic autoimmune disease whose symptoms occur before the age of $18 .^{3}$ The occurrence of pediatric SLE is about $10-20 \%$ of total SLE cases, with an incidence of 0.3-0.9 per

Correspondence: Hasti Savira Yudiana, Faculty of Medicine, Universitas Padjajaran, Jalan Raya Bandung Sumedang KM 21, Jatinangor, Sumedang Indonesia, E-mail: hasti_savira@yahoo.co.id 
100,000 children per year. The previous study has reported that children-onset has more diverse and heavier manifestation. ${ }^{1,4}$ Hematologic abnormality is one of the most common manifestations of SLE in children with approximately $50 \%$ of cases. Abnormalities hematologic interpretation in SLE consists of leukopenia, with lymphopenia, neutropenia, or both; anemia and thrombocytopenia. ${ }^{4-8}$ Therefore, the hematology examination is one of the most frequent examinations and criteria for identifying SLE patients based on the American College of Rheumatology (ACR) 1997 and The Systemic Lupus International Collaborating Clinics (SLICC) 2012. ${ }^{7,9,10}$ Children growth period contribute to the severity of pediatric SLE. ${ }^{1}$ Therefore, the identification of pediatric SLE becomes more challenging.

Dr. Hasan Sadikin General Hospital, as our study site, is a tertiary hospital, located in the West Java Province, admitting pediatric SLE patients with approximately 249 cases annually. A limited study has been done to identify the clinical manifestation and hematologic result among pediatric SLE at this population level, particularly for age-group in the children growth period. This study was conducted to have a better understanding of the clinical manifestation and hematologic interpretation of pediatric SLE at initial presentation.

\section{Methods}

This was a descriptive study with retrospective data, collected from patient medical records from 1 January 2017 to 31 December 2018. These two years period study was conducted at the Department of Child Health Dr. Hasan Sadikin General Hospital Bandung. This study retrieved and screened medical records for outpatient and inpatient according to the ICD10 diagnosis of Systemic Lupus Erythematosus
(ICD-10-CM Codes M32*). Screened data were selected based on inclusion and exclusion criteria. The inclusion criteria of this study were pediatric patients ( $<18$ years) with SLE based on ACR and SLICC ${ }^{3,10}$ who had complete hematologic examination such as hemoglobin, leukocytes, neutrophils, lymphocytes, platelets, and hematocrit at the time of initial diagnosis. The exclusion criteria were incomplete and unclear information data written in the medical record and an irregular routine visits to the hospital.

The variables used in this study were age, gender, and clinical manifestations that were categorized as malar rash, discoid rash, photosensitivity, oral ulcers, arthritis, renal disorders, and neurological disorders. Furthermore, data on hematology results, including hemoglobin levels, ery throcyte index i.e. MCV, MCH, MCHC, number of leukocytes, neutrophils, lymphocytes, and platelets were retrieved. The hematologic interpretation was defined and categorized into: anemia, leukopenia, neutropenia, lymphopenia, and thrombocytopenia. Anemia was designated as hemoglobin level $<11 \mathrm{~g} / \mathrm{dl}$ for children aged 6-59 months, <11.5d/dl for aged 5-11 years, and $<12 \mathrm{~d} / \mathrm{dL}$ for aged $>11$ years; Leukopenia was designated as leukocytes level $<4,000 /$ $\mathrm{mm}^{3}$, neutropenia as neutrophils level $<1,000 / \mathrm{mm}^{3}$, lymphopenia as lymphocytes level $<1500 / \mathrm{mm}^{3}$, and thrombocytopenia as thrombocytes level $<150,000 / \mathrm{mm}^{3} \cdot 4,5,8$ To analyze the clinical manifestation and hematologic interpretation, we had defined age group into three categories based on prepubertal growth period (male of age $\leq 9$ years old and female $\leq 8$ years old); peripubertal (male of age $>9-<14$ years old and female $>$ $8-<13$ years old); and post-pubertal (male $\geq 14$ years old and female $\geq 13$ years old). ${ }^{11}$

General demographic, clinical manifestation, and hematologic interpretation were presented as frequency, to present

Table 1 Hematological Values at Initial Presentation of Newly Diagnosed Systemic Lupus Erythematosus Pediatric Patients at the Department of Child Health, Dr. Hasan Sadikin General Hospital Bandung during 2017 and 2018

\begin{tabular}{lcc}
\hline \multicolumn{1}{c}{ Hematological value } & Median & IQR \\
\hline Hemoglobin Levels (g/dL) & 9.5 & $8.0-11.5$ \\
Leukocyte $\left(\mathrm{mm}^{3}\right)$ & 6,300 & $4,030-9,170$ \\
Neutrophils $\left(\mathrm{mm}^{3}\right)$ & 3,842 & $2,276-6,425$ \\
Lymphocyte $\left(\mathrm{mm}^{3}\right)$ & 1,460 & $857-2,232$ \\
Platelet $\left(\mathrm{mm}^{3}\right)$ & 229,000 & $152,000-329,000$ \\
Hematocrit Levels (\%) & 29.5 & $24.3-36.2$ \\
\hline
\end{tabular}

Note: IQR= interquartile range 


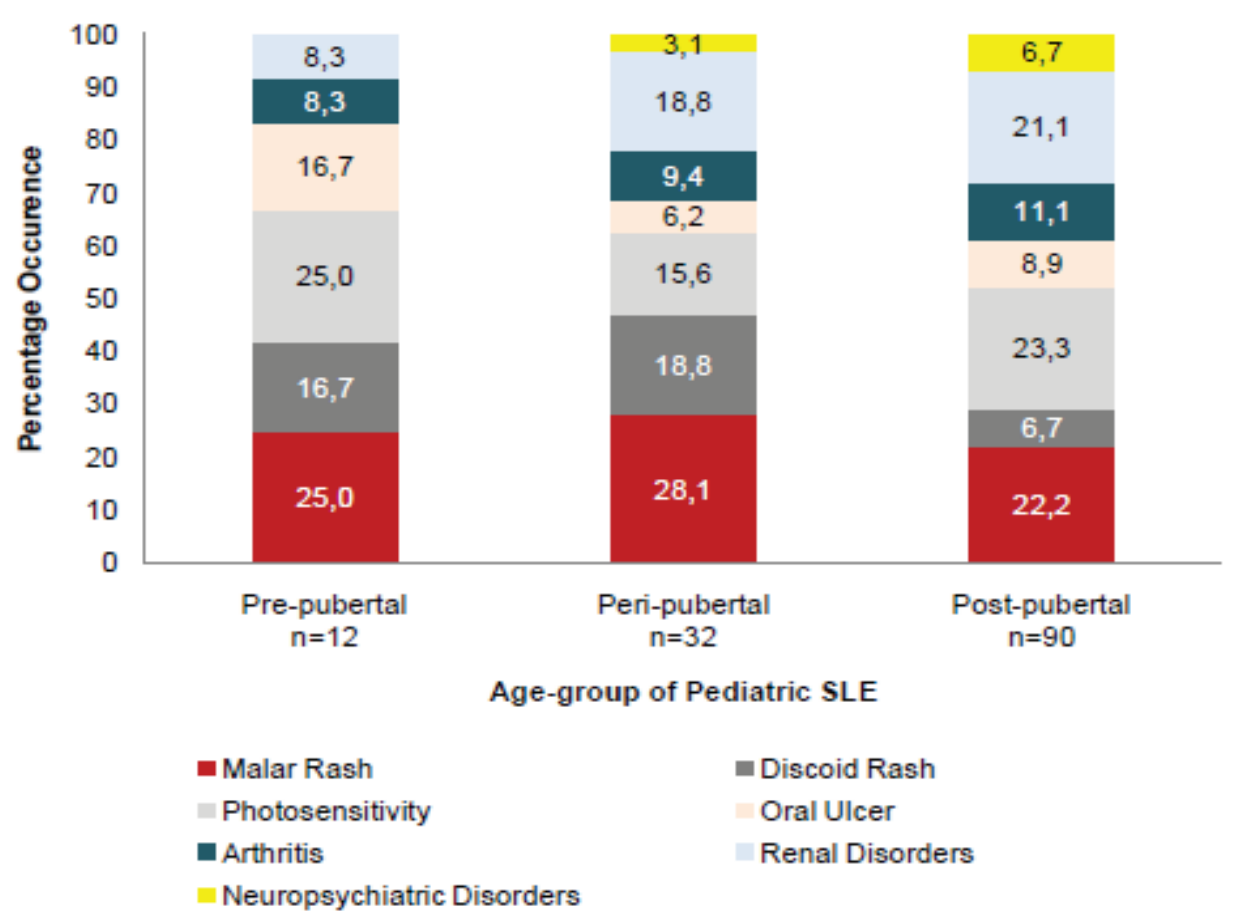

\section{Figure 1 Clinical Manifestations of Pediatric Systemic Lupus Erythematosus Patients based on Age Group}

Note: $\mathrm{n}=$ number of clinical manifestations frequency observed in 79 patients, which can have more than one clinical manifestation

the overall insight of the data population. The stratification with the age group was performed to observe the occurrence of clinical manifestation and hematologic interpretation among the age group category. All the data were analyzed using statistical software (IBM SPSS ver. 19, Chicago, IL, USA). This study was approved by the Ethics Committee of Universitas Padjadjaran (No.651/UN6.KEP/ EC/2019) and the Health Research Ethics Committee of Dr. Hasan Sadikin General Hospital (No.LB.02.01/X.2.2.1/10522/2019).

\section{Results}

A total of 185 data were screened according to the ICD-10-CM:M32, however, only 79 data fulfilled the inclusion criteria. Characteristics of newly diagnosed pediatric SLE patients at the Department of Child Health, Dr. Hasan Sadikin General Hospital Bandung between 1 January 2017 and 31 December 2018 were dominated by a female $(92.4 \%)$ with a ratio of male:female was 1:12. The median age of the cases was 14 years old (range 11-16 years). In general, anemia was observed at initial presentation among the pediatric SLE population $(n=61 ; 77.2 \%)$. The hematological values at the initial presentation were depicted in Table 1.

Based on the age group of pediatric SLE, the most common clinical manifestation at the onset of disease was malar rashes, which was found in the range $20-30 \%$ of all age-group. Photosensitivity was the second common clinical manifestation among the prepubertal and post-pubertal groups, $25 \%$, and $23.3 \%$, respectively. The renal disorders and discoid rashes were more likely to be found as a second clinical manifestation in the peripubertal group. The interesting findings were the increased trend of neurologic disorders occurrence and renal disorders among agegroup (Figure 1).

The occurrence of anemia was the most common hematological manifestation among all the age-group, ranging between $37.5-46 \%$. Lymphopenia, with or without 


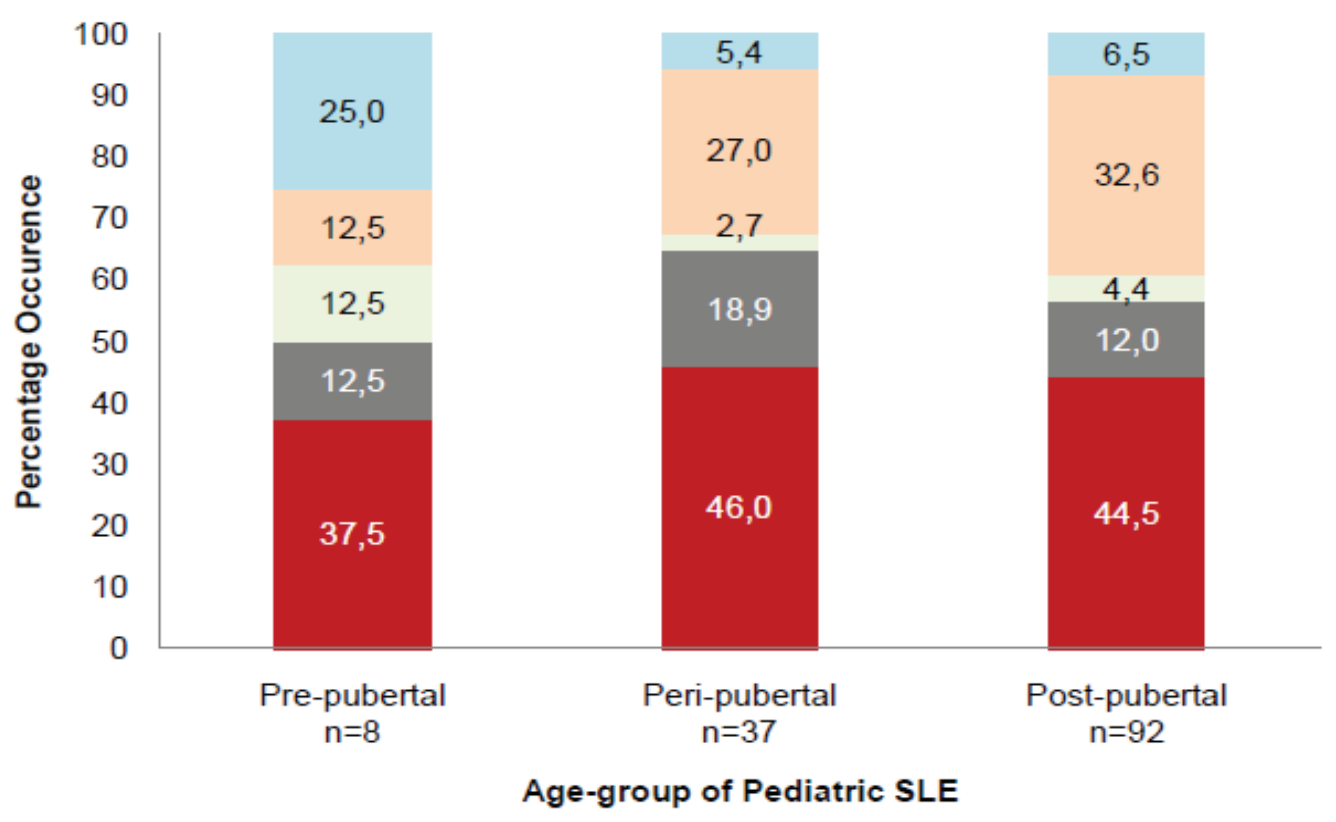

anemia Leukopenia Neutropenia Lymphopenia Thrombocytopenia

\section{Figure 2 Hematological Manifestation of Pediatric Systemic Lupus Erythematosus Patients Based on Age Group}

Note: $\mathrm{n}=$ number of clinical manifestations frequency observed in 79 patients, which can have more than one hematological manifestationn

leukopenia was observed as the second frequent hematological manifestation in peripubertal and post-pubertal, $27 \%$ and $32.6 \%$, respectively. Meanwhile, the occurrence of thrombocytopenia was found more frequent in pre-pubertal (25\%). Among all the hematological manifestations, such as anemia with thrombocytopenia, anemia with lymphopenia, or anemia, leukopenia and lymphopenia, were a frequent combination of hematological manifestations among the pediatric SLE populations (Figure 2).

\section{Discussion}

This study shows the initial presentation of clinical manifestation and hematologic interpretation of pediatric SLE, which is important to the identification of SLE. In this study, the clinical manifestations from pediatric SLE are very diverse, both in terms of numbers and types of abnormalities.

Malar rashes are the most common clinical manifestation in all age groups category within this study. This finding is similar to the previous report, which observes mucocutaneous disorder, especially malar rashes, occurs in almost every case of SLE. ${ }^{12}$ The main cause of the malar rash is UV light that stimulates keratinocytes to produce innate cytokine and trigger cell death, and promote inflammatory infiltrates which damage skin tissues. ${ }^{13}$ Skin disorders likely to be the easiest finding to recognize and to examine, either by patients or by physicians. ${ }^{14}$ Therefore, the malar rashes are the important finding of this study.

Neuropsychiatric disorders or NPSLE and renal disorders are among the causes of mortality and morbidity in children with SLE. ${ }^{3,15}$ In this study, the occurrence of NPSLE and renal disorder increased among the age groups. NPSLE is caused by autoantibody production, micro-angiopathy, intrathecal production of pro-inflammatory cytokines, and premature atherosclerosis that disturb the integrity of the blood-brain barrier and allow, thus, more proteins or cells access to the CNS. ${ }^{15,16}$ The mechanism of renal disorder is the deposition of the antigen-antibody complex on glomeruli and promotes inflammation and adjacent cell proliferation such as endothelial cells, epithelial cells, and mesangial cells. ${ }^{3,4,15}$ 
Although the previous study has shown that renal and neuropsychiatric disorders were the most commonly found clinical manifestations in the pre-pubertal group, however, we observe in our current study that the occurrence of the renal disorder increases with the agegroup due to complexity of the disease to the body metabolism. On the other hand, NPSLE is more likely to occur in older age due to difficulties observing psychiatric symptoms in small children. Moreover, a neuropsychiatric disorder is usually found at a follow-up or in the first year after the first diagnosis of SLE is done. ${ }^{3,4,15,16}$

Hematologic abnormalities present as high as $83.5 \%$ among all pediatric SLE, and anemia is the most common abnormality. Specific autoantibodies might directly attack, opsonize, phagocyte, and lyse erythrocytes, leukocytes, and thrombocytes, leading to the decreased amount in the blood. ${ }^{17}$ Anemia is generally caused by several factors i.e. low erythropoiesis due to low erythropoietin in chronic disease; low levels of ferritin, and hemolytic anemia. The occurrence of anemia reported by other studies is ranging between $50-70 \%{ }^{6,18}$

Leukopenia, with or without lymphopenia or neutropenia, and thrombocytopenia are also common in pediatric SLE. ${ }^{5,19}$ Leukopenia can be accompanied by lymphopenia, neutropenia, or both. Lymphopenia in SLE is generally caused by a decreased number of $T$ and $B$ lymphocytes due to an increased number of natural killer cells, a decreased number of proteins that regulate complement, resulting in complement-mediated lysis. Furthermore, it can be caused by the presence of cytotoxic anti-lymphocyte antibodies. ${ }^{5,18}$ The number of pediatric SLE with lymphopenia increases, in line with the increase of age when the first diagnosis of SLE. Leukopenia can also be caused or worsened by the use of immunosuppressant drugs that may suppress the bone marrow. ${ }^{5,19}$ Thrombocytopenia in SLE is generally caused by the increase of platelet destruction and the presence of anti-platelet antibodies that might attack antigens on the surface of the platelet. In addition, similar to leukopenia, thrombocytopenia can also be caused by the use of immunosuppressant drugs, which can interfere with platelet production. ${ }^{5}$

Limitations of this study are among others the small numbers of pediatric SLE cases over two years of study, which may lead to an overestimated percentage of occurrences among the age groups. There is limited information in examinations available to determine other causes of various hematologic abnormalities. Further study recruiting more cases is of great interest, therefore, the age-group population could be distributed evenly, which can present the actual estimated number of occurrence of both clinical manifestation and hematologic interpretation in pediatric SLE patients.

In conclusion, clinical manifestation and hematologic interpretation of pediatric SLE patients are important factors. Malar rash and anemia are the common findings among all age-group of pediatric SLE patients. The occurrences of neuropsychiatric and renal disorder among age-group are observed as important finding in this study.

\section{References}

1. Pons-Estel GJ, Ugarte-Gil MF, Alarcón GS. Epidemiology of systemic lupus erythematosus. Expert Rev Clin Immunol. 2017;13(8):799-814.

2. Pusat Data dan Informasi Kementrian Kesehatan Republik Indonesia. Situasi lupus di Indonesia. Jakarta: Kementrian. Kesehatan.Republik Indonesia; 2017. p. 1-7. [cited 2019 Feb 22]. Available form: https://pusdatin.kemkes.go.id

3. Aggarwal A, Srivastava P. Childhood onset systemic lupus erythematosus: how is it different from adult SLE? Int J Rheum Dis. 2015;18(2):182-91.

4. Levy DM, Kamphuis S. Systemic lupus erythematosus in children and adolescents. Pediatric Clin North Am. 2012;59(2):34564.

5. Bashal F. Hematological disorders in patients with systemic lupus erythematosus. Open Rheumatol J. 2013;7:87-95.

6. Thakur N, Chandra J, Dhingra B, Singh V. Pediatric lupus: varied haematological picture and presentation. Indian J Hematol Blood Transfus. 2015;31(1):68-70.

7. Tarr T, Dérfalvi B, Győri N, Szántó A, Siminszky Z, Malik A, et al. Similarities and differences between pediatric and adult patients with systemic lupus erythematosus. Lupus. 2015;24(8):796-803.

8. Oehadian A, Suryadinata $H$, Dewi $S$, Pramudyo R, Alisjahbana B. The role of neutrophyl lymphocyte count ratio as an inflammatory marker in systemic lupus erythematosus. Acta Med Indones. 2013;45(3):170-4.

9. Kasjmir YI, Handono K, Wijaya LK, Hamijoyo L, Albar Z, Kalim H, et al. Rekomendasi Perhimpunan Reumatologi 
Indonesia: diagnosis dan pengelolaan lupus eritematosus sistemik. Jakarta: Perhimpunan Ahli Penyakit Dalam Indonesia; 2011. p. 1-46 [cited 2019 May 8] Available form: http://reumatologi. or.id/

10. Karuniawaty TP, Sumadiono S, Satria CD. Perbandingan diagnosis systemic lupus erythematosus menggunakan kriteria American College of Rheumatologi dan Systemic Lupus International Collaborating Clinics. Sari Pediatri. 2017;18(4):299-303.

11. Abdwani R, Abdalla E, Al-Zakwani I. Unique characteristics of prepubertal onset systemic lupus erythematosus. International Journal of Pediatrics. 2019;2019:9537065.

12. Ghrahani R, Setiabudiawan B, Sapartini G. Pola antibodi antinuklear sebagai faktor risiko keterlibatan sistem hematologi lupus eritematosus sistemik pada anak. Majalah Kedokteran Bandung. 2015;47(2):124-8.

13. Stannard JN, Kahlenberg JM. Cutaneous lupus erythematosus: updates on pathogenesis and associations with systemic lupus. Curr Opin Rheumatol. 2016;28(5):453-9.

14. Evalina R. Gambaran klinis dan kelainan imunologis pada anak dengan lupus eritematosus sistemik di Rumah Sakit
Umum Pusat Adam Malik Medan. Sari Pediatri. 2016;13(6):406-11.

15. Soybilgic A. Neuropsychiatric systemic lupus erythematosus in children. Pediatric Ann. 2015;44(6):e153-8.

16. Muscal E, Brey RL. Neurological manifestations of systemic lupus erythematosus in children and adults. Neurol Clin. 2010;28(1):61-73.

17. Sasidharan P, Bindya M, Sajeeth Kumar K. Hematological manifestations of SLE at initial presentation: is it underestimated? ISRN Hematol. 2012;2012:961872.

18. Janoudi N, Bardisi ES. Haematological manifestations in systemic lupus erythematosus. In: Almoallim DH, editor. Systemic lupus erythematosus. London: InTechOpen; 2012. p. 363-82. [cited 2019 Feb 22] Available from: https:// www.intechopen.com/books/systemiclupus-erythematosus/haematologicalmanifestations-in-systemic-lupuserythematosus

19. Carli L, Tani C, Vagnani S, Signorini V, Mosca M. Leukopenia, lymphopenia, and neutropenia in systemic lupus erythematosus: prevalence and clinical impact-a systematic literature review. Semin Arthritis Rheum. 2015;45(2):190-4. 